NASA/TM-2003-212532

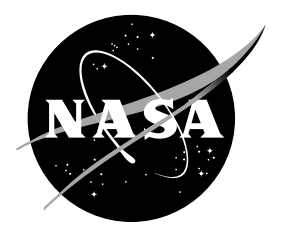

\title{
Effect of Individual Component Life Distribution on Engine Life Prediction
}

Erwin V. Zaretsky and Robert C. Hendricks

Glenn Research Center, Cleveland, Ohio

Sherry M. Soditus

United Airlines Maintenance, San Francisco, California 
Since its founding, NASA has been dedicated to the advancement of aeronautics and space science. The NASA Scientific and Technical Information (STI) Program Office plays a key part in helping NASA maintain this important role.

The NASA STI Program Office is operated by Langley Research Center, the Lead Center for NASA's scientific and technical information. The NASA STI Program Office provides access to the NASA STI Database, the largest collection of aeronautical and space science STI in the world. The Program Office is also NASA's institutional mechanism for disseminating the results of its research and development activities. These results are published by NASA in the NASA STI Report Series, which includes the following report types:

- $\quad$ TECHNICAL PUBLICATION. Reports of completed research or a major significant phase of research that present the results of NASA programs and include extensive data or theoretical analysis. Includes compilations of significant scientific and technical data and information deemed to be of continuing reference value. NASA's counterpart of peerreviewed formal professional papers but has less stringent limitations on manuscript length and extent of graphic presentations.

- TECHNICAL MEMORANDUM. Scientific and technical findings that are preliminary or of specialized interest, e.g., quick release reports, working papers, and bibliographies that contain minimal annotation. Does not contain extensive analysis.

- CONTRACTOR REPORT. Scientific and technical findings by NASA-sponsored contractors and grantees.
- CONFERENCE PUBLICATION. Collected papers from scientific and technical conferences, symposia, seminars, or other meetings sponsored or cosponsored by NASA.

- SPECIAL PUBLICATION. Scientific, technical, or historical information from NASA programs, projects, and missions, often concerned with subjects having substantial public interest.

- TECHNICAL TRANSLATION. Englishlanguage translations of foreign scientific and technical material pertinent to NASA's mission.

Specialized services that complement the STI Program Office's diverse offerings include creating custom thesauri, building customized databases, organizing and publishing research results ... even providing videos.

For more information about the NASA STI Program Office, see the following:

- Access the NASA STI Program Home Page at http://www.sti.nasa.gov

- E-mail your question via the Internet to help@sti.nasa.gov

- Fax your question to the NASA Access Help Desk at 301-621-0134

- Telephone the NASA Access Help Desk at 301-621-0390

- Write to:

NASA Access Help Desk

NASA Center for AeroSpace Information 7121 Standard Drive

Hanover, MD 21076 
NASA/TM-2003-212532

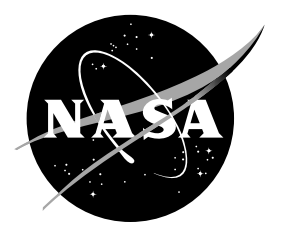

\section{Effect of Individual Component Life Distribution on Engine Life Prediction}

Erwin V. Zaretsky and Robert C. Hendricks

Glenn Research Center, Cleveland, Ohio

Sherry M. Soditus

United Airlines Maintenance, San Francisco, California

Prepared for the

Symposium on Probabilistic Aspects of Life Predictions

sponsored by the ASTM Committee E08 on Fatigue and Fracture

Miami Beach, Florida, November 6-7, 2002

National Aeronautics and

Space Administration

Glenn Research Center 
Available from

NASA Center for Aerospace Information 7121 Standard Drive

Hanover, MD 21076
National Technical Information Service 5285 Port Royal Road Springfield, VA 22100

Available electronically at http://gltrs.grc.nasa.gov 


\title{
Effect of Individual Component Life Distribution on Engine Life Prediction
}

\author{
Erwin V. Zaretsky ${ }^{1}$ and Robert C. Hendricks ${ }^{2}$ \\ National Aeronautics and Space Administration \\ Glenn Research Center \\ Cleveland, Ohio 44135 \\ Sherry M. Soditus ${ }^{3}$ \\ United Airlines Maintenance \\ San Francisco, California 94128
}

\begin{abstract}
The effect of individual engine component life distributions on engine life prediction was determined. A Weibull-based life and reliability analysis of the NASA Energy Efficient Engine was conducted. The engine's life at a 95 and 99.9 percent probability of survival was determined based upon the engine manufacturer's original life calculations and assumed values of each of the component's cumulative life distributions as represented by a Weibull slope. The lives of the high-pressure turbine (HPT) disks and blades were also evaluated individually and as a system in a similar manner. Knowing the statistical cumulative distribution of each engine component with reasonable engineering certainty is a condition precedent to predicting the life and reliability of an entire engine. The life of a system at a given reliability will be less than the lowest-lived component in the system at the same reliability (probability of survival). Where Weibull slopes of all the engine components are equal, the Weibull slope had a minimal effect on engine $L_{0.1}$ life prediction. However, at a probability of survival of 95 percent ( $L_{5}$ life), life decreased with increasing Weibull slope.
\end{abstract}

\section{Nomenclature}

e Weibull slope or Weibull modulus

$F \quad$ probability of failure, fraction or percent

$L \quad$ life, hr or number of stress cycles

$L_{1}, L_{n} \quad$ cumulative life of each engine component, hr or number of stress cycles

$\mathbf{L}_{1}, \mathbf{L}_{n} \quad$ engine life at each power setting, hr or number of stress cycles

$L_{0.1} \quad 0.1$ percent life or life at which 99.9 percent of population survives, hr or number of stress cycles

$L_{5} \quad 5$ percent life or life at which 95 percent of population survives, hr or number of stress cycles

\footnotetext{
${ }^{1}$ Chief Engineer for Structures and Acoustics

${ }^{2}$ Senior Technologist

${ }^{3}$ Senior Engineer
} 


\begin{tabular}{|c|c|}
\hline$L_{u}$ & location parameter, life below which no failures will occur, \\
\hline$L_{\beta}$ & characteristic life at which 63.2 percent of population fails, \\
\hline & $\mathrm{hr}$ or number of stress cycles \\
\hline$n$ & exponent or number of system components \\
\hline & load-life exponent \\
\hline & probability of survival, fraction or percent \\
\hline$T$ & engine thrust load, $\mathrm{N}\left(\mathrm{lb}_{\mathrm{f}}\right)$ \\
\hline$X$ & load, time or stress \\
\hline$X_{1}, X_{2}$ & fractional time at load and/or speed for related lives $\mathbf{L}_{1}$ and $\mathbf{L}_{2}$ \\
\hline \multicolumn{2}{|l|}{ Subscripts } \\
\hline blade & blade or blades \\
\hline HPT & high-pressure turbine \\
\hline$i$ & initial value \\
\hline$n$ & number of components or elemental volumes \\
\hline RE & remainder of engine components \\
\hline & reference point or life \\
\hline ROT. ST. & rotating structure (disks, drums) \\
\hline & system or component probability of survival or life \\
\hline & characteristic life or stress \\
\hline
\end{tabular}

\section{Introduction}

Operation of the airline industry is very expensive and the profit margin is extremely small. In general, new technology, first-run engines will get upward of $20000 \mathrm{hr}$ of operation before refurbishment. Operating times for second-run engines before refurbishment are less than those of first-run engines.

The service life of an aircraft gas turbine engine is based upon deterministic calculations of low-cycle fatigue (LCF) and previous field experience with similar engines. It is probable that no two engine companies determine the life of their engines in the same way or apply the same experience and/or safety factors to their designs. This can be readily illustrated in the reported life estimates of the NASA Energy Efficient Engine ( $E^{3}$-Engine) shown in Figure 1. Davis and Stearns [1] determined the life of the engine based upon its similarity to their maintenance experience with a commercial engine having similarly designed components.

Many design engineers use a probabilistic approach wherein a normal or log-normal distribution is assumed about a calculated or experimental mean value of life and a 99.9 percent probability of survival is calculated. This would imply that 1 in 1000 of the same components would be removed for cause prior to reaching the calculated or projected time.

Davis and Stearns [1] and Halila et al. [2] discuss the mechanical and analytical methods and procedures for turbine engine and HPT design. The designs for the engine components are based on life predictions by using material test curves that relate life in cycles and/or time (hours) as a function of stress. Six criteria for failure were presented: 1. Stress rupture, 2. Creep, 3. Yield, 4. Low-cycle fatigue (LCF), 5. High-cycle fatigue (HCF), and 6. Fracture mechanics.

A discussion of each criterion above is beyond the scope of this paper. However, it can reasonably be concluded that items 1 and 2 are defined by steady-state stress and time at load 


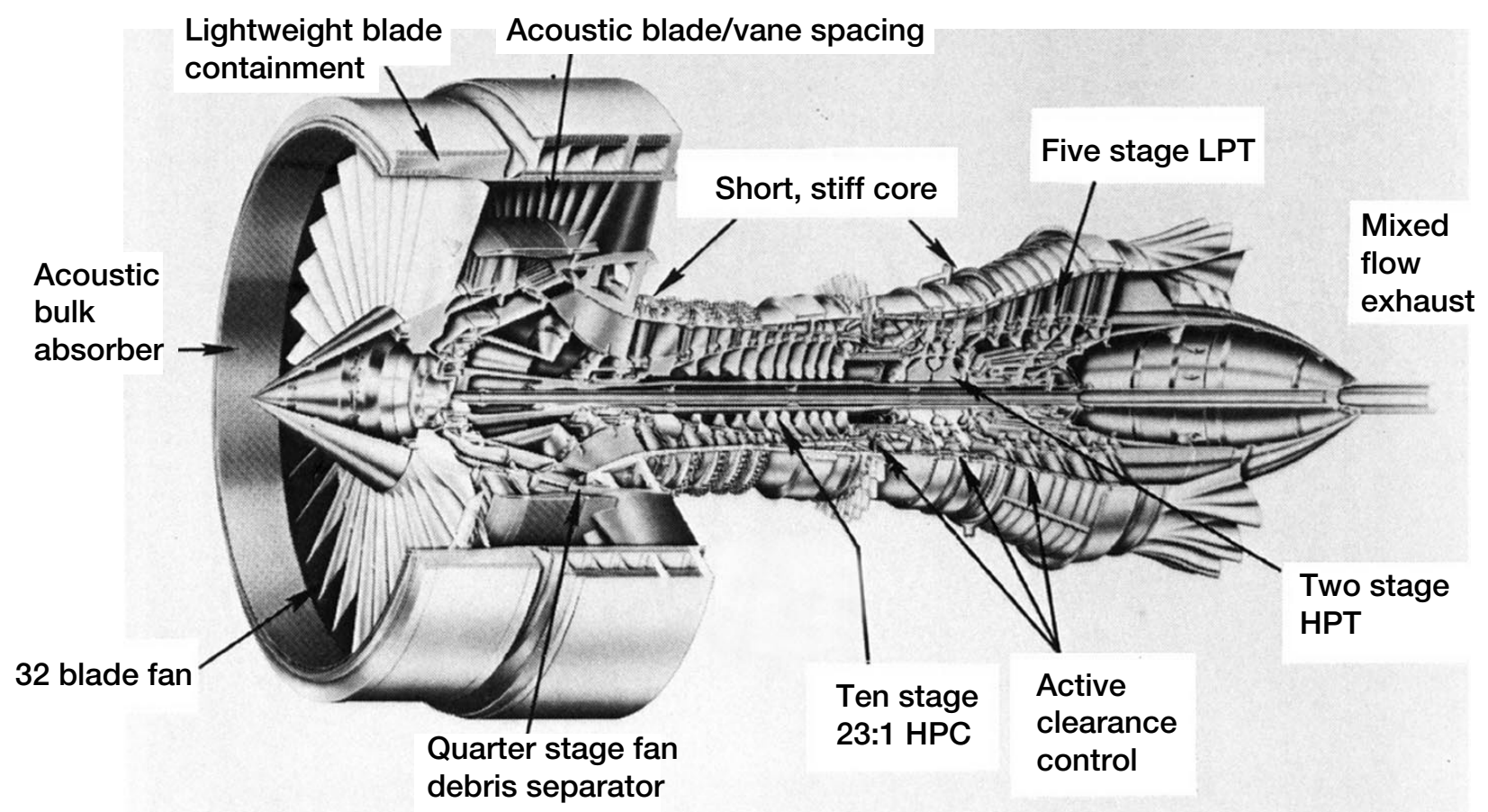

FIG. 1-Energy efficient ( $\left.E^{3}-\right)$ engine.

and temperature. Items 3 and 6 are defined by stress and temperature and are generally considered independent of time. Where limits are placed on stress, temperature, and time for a component's design, the criteria that will define the component's life and thus the engine's life will be either HCF or LCF. At high temperature, it is difficult to determine a fatigue limit or a stress below which no failure will occur for most aerospace materials. Failures are statistically distributive; that is, the ratio of time between the first component failure and the last in a population can be 1 or 2 orders of magnitude. All materials and/or components will not have the same cumulative failure distribution curve (Weibull slope).

A major omission by many in determining the life and reliability of the various components is consideration of the component size (stressed volume) and the number of components of a given type and design in the operating system. This omission in stressed volume was recognized by Weibull [3,4] and incorporated into his Weibull distribution function. As an example, for a given stress distribution, a turbine disk having less material volume and/or a smaller number of bolt holes will have a longer LCF life at a given probability of survival than a larger disk of the same design [5] . In many designs, the life of a single component is incorrectly based on the life of the stressed-volume having the highest single-stressed value independent of other stressed points in the body. This can result in over predicting the component's life [6]. It is also not possible to accurately relate individual coupon fatigue and fracture strength data to component life and reliability without considering the effect of stressed volume or the number of elements in the system [7].

Using the Weibull analysis and the Lundberg-Palmgren [8] theory, Lewicki et al. [9] determined the fatigue life of an Allison T56/501-D22A gearbox based on a typical operating 
profile. Excellent correlation was obtained between the predicted lives and actual field data. To the best of our knowledge, a Weibull-type reliability (failure probability) analysis similar to that of Lewicki et al. (1986) has not been performed on an aircraft gas turbine engine as an entire system.

Unfortunately, the life distributions for most engine related components have either not been determined with reasonable engineering and/or statistical certainty or have not been published. In order to perform a probabilistic life analysis it becomes incumbent upon the designer or analyst to assume a life and reliability distribution of each engine component. Based upon our previous reported work [10], it is the objective of the work reported herein to determine the effect of assuming component life distributions on engine life prediction and reliability.

\section{Weibull Probability Analysis}

A typical scenario that can be adopted to design an aircraft engine for life and reliability is to assume a typical flight (profile) cycle and specify a life in flight hours and a reliability for the engine. Usually an engine is removed for cause, degraded performance, and/or because it has reached its specified design life. Any engine event that will require removal of the engine from the aircraft and/or removal of the aircraft from scheduled service can be designated a failure. The engine can be removed or repaired for cause and/or for an expired time before an anticipated failure can occur. A component in the engine is failed when it is no longer fit for its intended purpose even though it is still functional. A component is removed before it can cause secondary damage to the engine.

When specifying a design life, an acceptable reliability also needs to be specified; that is, how many incidents of engine removal for cause is the end user airline willing to experience before the engine design life is reached. As an example, if there were a fleet of 1000 engines and the end user was willing to accept that 50 engines would be removed for cause before the design life was reached, the engine could be considered to operate at a 5 percent removal (failure) rate or at a 95 percent probability of survival. This number does not anticipate "infant mortality" or "human factors" in the analysis. Although, based on experience or a previously existing database, these causes may be factored into a final analysis. However, for the purpose of this paper and the resulting analysis, infant mortality, and human factors are not considered.

Figure 2 shows, generically, a typical flight profile for the NASA E ${ }^{3}$-Engine [1]. There are 15 power settings for this engine during the flight cycle. Using the required engine design life for this typical flight cycle at a 95 percent probability of survival, the engine life can be determined at each power setting using the linear damage (Palmgren-Langer-Miner) rule [11-13] where

$$
\frac{1}{\mathbf{L}_{s y s}}=\frac{X_{1}}{\mathbf{L}_{1}}+\frac{X_{2}}{\mathbf{L}_{2}}+\ldots \frac{X_{n}}{\mathbf{L}_{n}}
$$

and assuming that the engine life is inversely proportional to the engine thrust load $T$ (power setting) to a power $p$ where

$$
L \sim \frac{1}{T^{p}}
$$




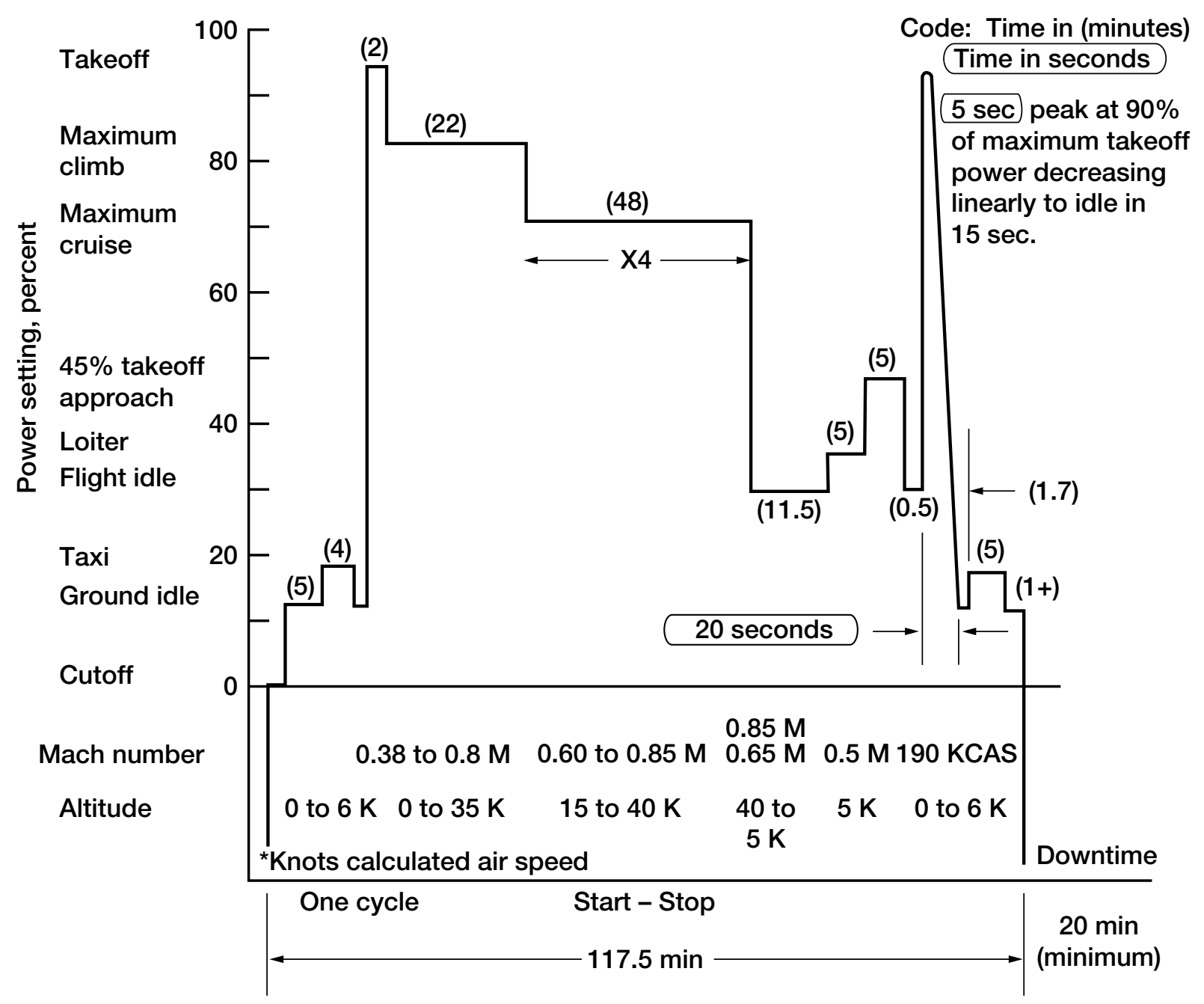

FIG. 2-E $E^{3}$-Engine typical flight cycle (from [1]).

The cumulative life of each of the engine components illustrated in the Weibull plots of Figure 3 can be combined to determine the calculated engine system life $L_{\mathrm{sys}}$ using the LundbergPalmgren formula $[8]$ :

$$
\frac{1}{L_{s y s}^{e}}=\frac{1}{L_{1}^{e_{1}}}+\frac{1}{L_{2}^{e_{2}}}+\ldots+\frac{1}{L_{n}^{e_{n}}}
$$

Equation (3) is derived from the Weibull equation [3, 4, 14]. The derivation of the Weibull equation is shown in Appendix A. The derivation of Eq. (3) is shown in Appendix B [6] where $e_{1}=e_{2}=\ldots=e_{n}$.

Referring to Eq. (3), the Weibull slope is designated by the symbol $e$ and is indicative of the dispersion of engine and/or component failure and/or replacement data for an entire engine or a single component when plotted on Weibull coordinates. Weibull slopes $e$ of 1, 2, and 3.57 are representative of exponential, Raleigh, and normal (Gaussian) distributions (Fig. 4) [15]. The life distribution of a component and thus the Weibull slope is a function of the material from which it 
is made, the manufacturing process including tolerances, and operating variables that deviate from defined steady-state conditions. Because of the lack of a definitive statistical database, the statistical distributions and thus the Weibull slope of most, if not all, engine components is assumed and/or is estimated.

The effect of Weibull slope on cumulative engine replacement where the engine $L_{0.1}$ life is assumed to be $9000 \mathrm{hr}$ is shown in Figure 5. The Weibull distribution function relating the probability of failure to engine life is as follows:

$$
\ln \ln \frac{1}{(1-F)}=e \ln \left(\frac{L}{L_{p}}\right)
$$

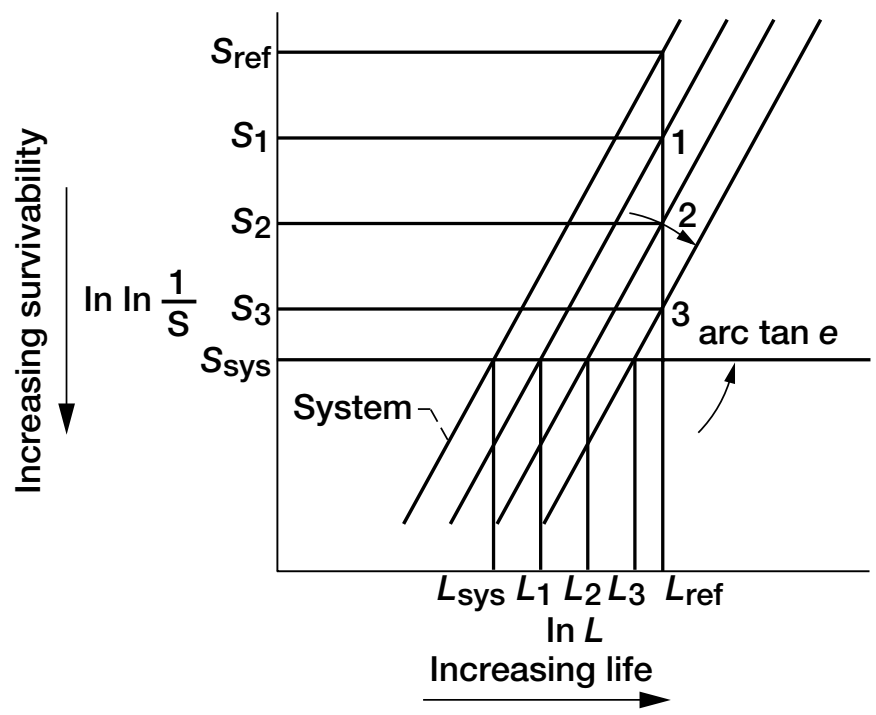

FIG. 3-Determination of system life from multiple components based on Weibull statistical analysis.

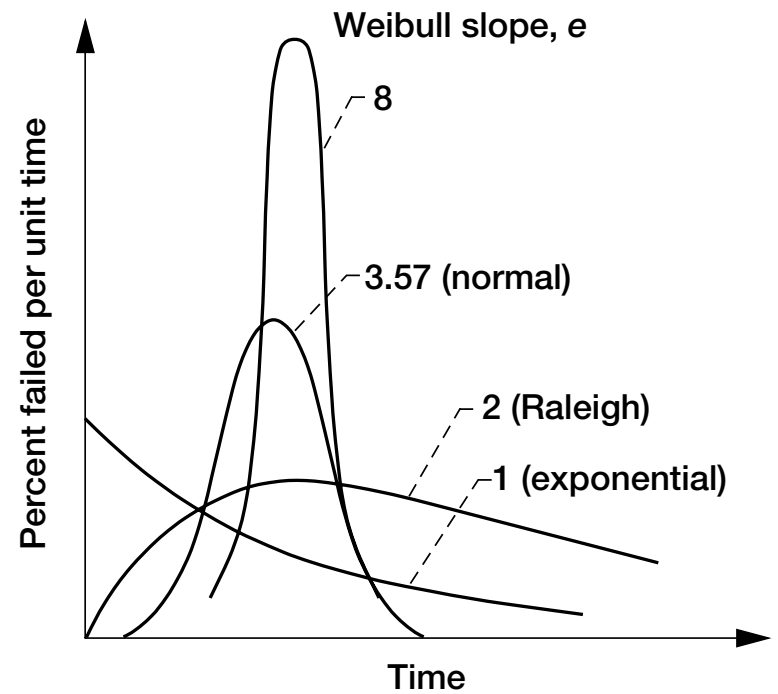

FIG. 4-Density distribution for various Weibull slopes. 


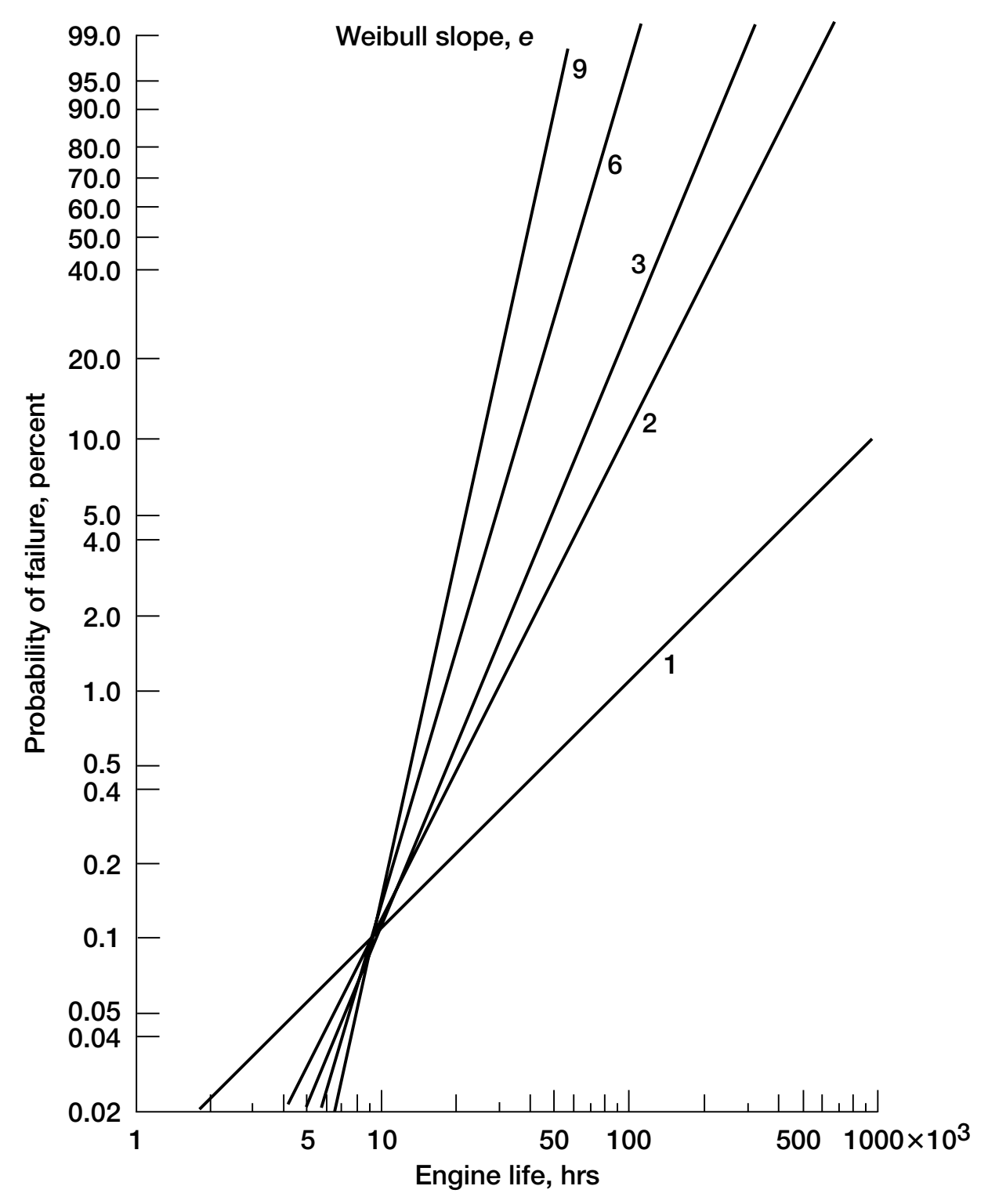

FIG. 5-Effect of Weibull slope e on cumulative engine replacement.

\section{Results and Discussion}

\section{Engine Life}

The NASA $E^{3}$-Engine was used as the basis of the Weibull-based life and reliability analysis reported in this paper. The engine, which was successfully fabricated and tested, was a cleansheet derivative of the GE CF6-50C engine. Each of the component systems of interest for this investigation and analysis is summarized in Table 1, which represents 1985 engine technology.

Referring to Eq. (3), when predicting engine life and reliability, knowing the Weibull slope, $e$, (cumulative life distribution) and characteristic life $L_{\beta}$ of each of the components making up the engine is a prerequisite to predicting the life and reliability of the entire engine. It is also important for logistic planning to determine the rate at which components and engines will need 
Table 1-Energy Efficient Engine (E ${ }^{3}$-) Flight Propulsion System (FPS) Life Based on 1985 Technology and Experience (Assume Service $L_{0.1}$ Life at 99.9 Percent Probability of Survival) [1]

\begin{tabular}{lcc}
\hline & $\begin{array}{c}\text { Service life, } \\
\mathrm{hr}\end{array}$ & Total life with repair, hr \\
\hline Combustor & 9000 & 18000 \\
HPT rotating structure & 18000 & 36000 \\
HPT blading & 9000 & 18000 \\
Remainder of engine & $\ldots$ & 36000 \\
\hline
\end{tabular}

replacement and/or repair. As previously discussed, Davis and Stearns [1] and Halila et al. [2] determined the life of the engine based upon its similarity to their maintenance experience with a commercial engine having similarly designed components. These life estimates are shown in Table 1. We assumed that the life estimates in Table 1 represent the 99.9 percent probability of survival $\left(L_{0.1}\right.$ life) for each of the component systems. The $L_{0.1}$ and $L_{5}$ lives are the times on or before which 0.1 and 5 percent of the engines will be removed from service because of cause, respectively. That is, out of 1000 engines, 1 engine will be removed at the $L_{0.1}$ life and 50 engines will have been removed at the $L_{5}$ life. Using Eq. (3), we calculated the $L_{0.1}$ lives of the entire engine for assumed combinations of Weibull slopes equal to 3, 6, and 9 for the HPT blade, HPT rotating structure, and the remainder of the engine as follows:

$$
\frac{1}{L_{\text {Sys }}^{e_{\text {sys }}}}=\frac{1}{L_{\text {HPT blade }}^{e_{1}}}+\frac{1}{L_{\text {HPT ROT. ST. }}^{e_{2}}}+\frac{1}{L_{R E}^{e_{3}}}
$$

The Weibull slope for the entire engine system was assumed to be the same as that for the turbine blades. According to Davis and Stearns [1] and Halila et al. [2], the HPT blades are the lowest lived components in this engine. Using Eq. (4), we calculated the $L_{5}$ from the results of Eq. (5).

The results of our analysis of the engine $L_{0.1}$ life are shown in Figure 6 for varying combinations of Weibull slope. Where service life of each component ranged from 9000 to $36000 \mathrm{hr}$ at a 99.9 percent probability of survival ( $L_{0.1}$ life), the predicted engine removal time for varying combinations of component statistical distributions varied from 26 to $8992 \mathrm{hr}$. The least variation and the highest predicted lives occur with a HPT blade and an engine Weibull slope of 3. This is a nearly normal distribution (Fig. 4). Although, we do not know with reasonable engineering certainty that these assumed distributions (Weibull slopes) actually represent those found in an engine, they show that vast differences and errors in predicted life and engine replacement can occur. Hence, knowing the statistical cumulative distribution of each engine component with reasonable engineering certainty is a condition precedent to predicting the life and reliability of an entire engine.

We assumed that the general cause for removal of the combustor is erosion wear and not fatigue. Experience has shown that while a damaged or cracked combustor inner liner has a small effect on engine performance, it has not been a cause for engine removal and/or secondary damage. A damaged combustor is replaced only when the engine is removed for other causes. As a result, we did not include the combustor in our life calculators. 
Remaining engine components except HPT blades Weibull slope, $e$

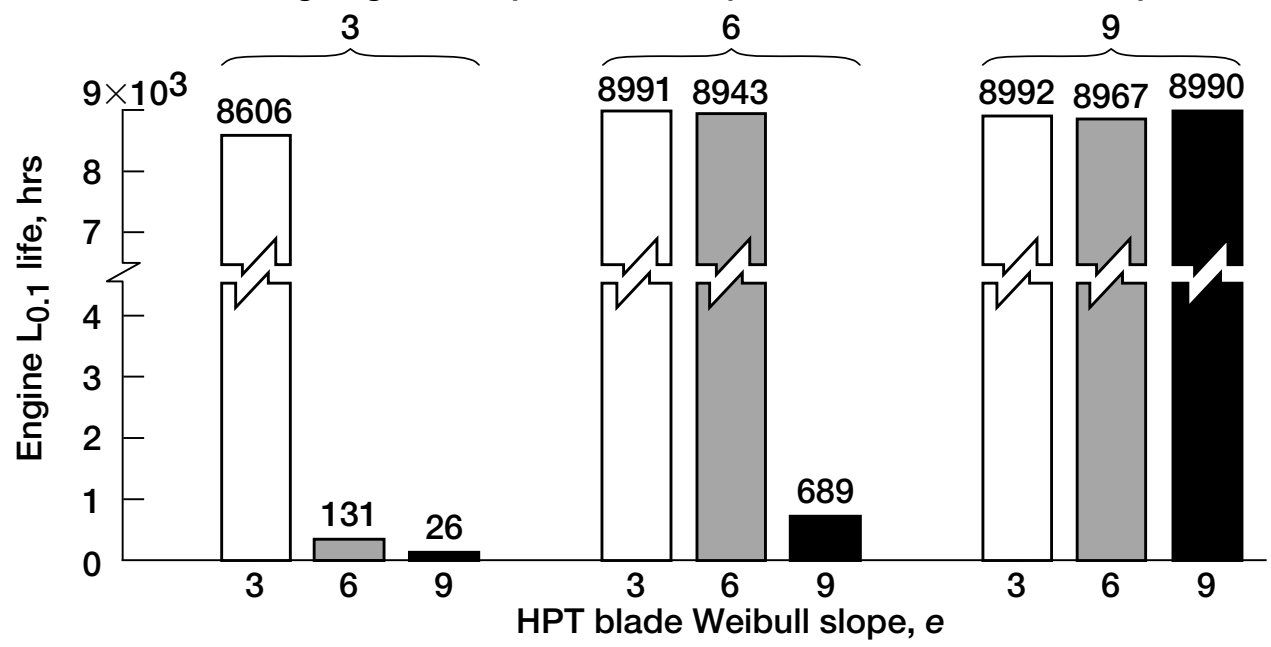

(a)

Remaining engine components except HPT and rotating structure Weibull slope, e

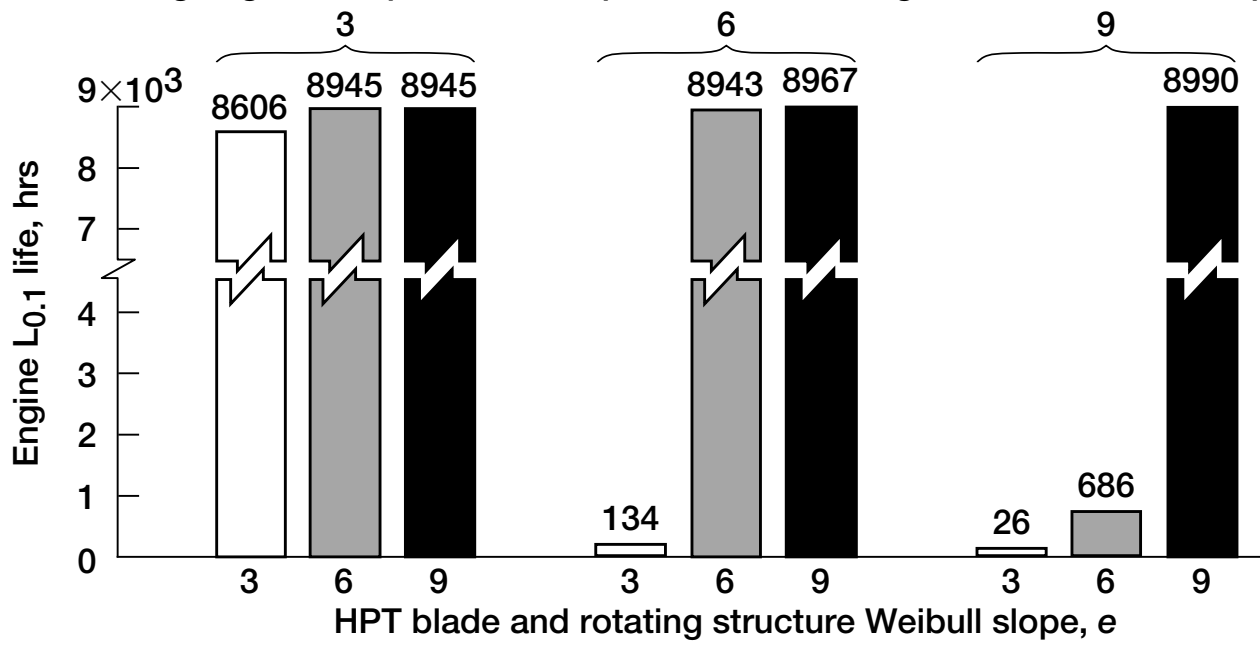

(b)

Combined HPT blade and rotating structure Weibull slope, e

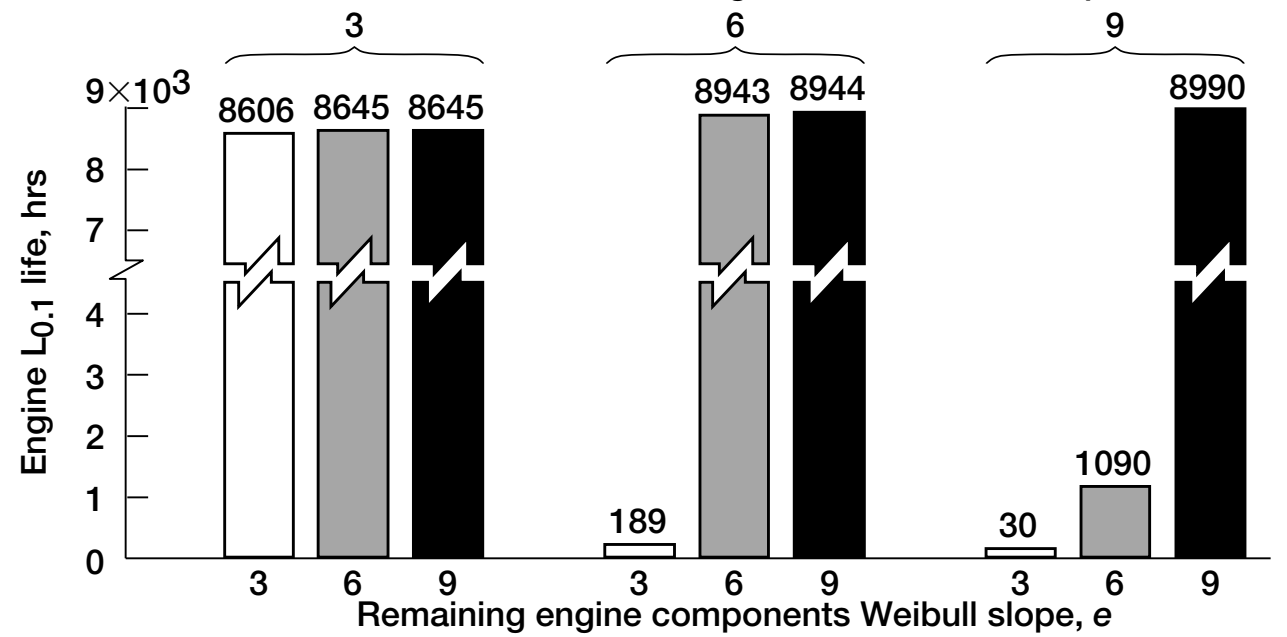

(c)

FIG. 6-Effect of engine component Weibull slope combinations on engine $L_{0.1}$ life. (a) HPT blade. (b) HPT blade and rotating structure. (c) Remaining engine components (except HPT blade and rotating structure). 
Figure 7 compares the $L_{0.1}$ and $L_{5}$ lives as a function of engine Weibull slope where the Weibull slopes of all the respective engine components are equal. The Weibull slope had a minimal effect on engine $L_{0.1}$ life prediction. Predicted engine $L_{0.1}$ life varied from 8606 to $8990 \mathrm{hr}$ for Weibull slopes of 3 to 9, respectively. However, at a probability of survival of 95 percent ( $L_{5}$ life), engine $L_{5}$ life decreased with increasing Weibull slope varying from 32009 to $13923 \mathrm{hr}$ for Weibull slopes ranging from 3 to 9 . At the $L_{5}$ life, five percent of the engines in service will have been removed for repair or refurbishment usually because of a decrease in engine efficiency measured as

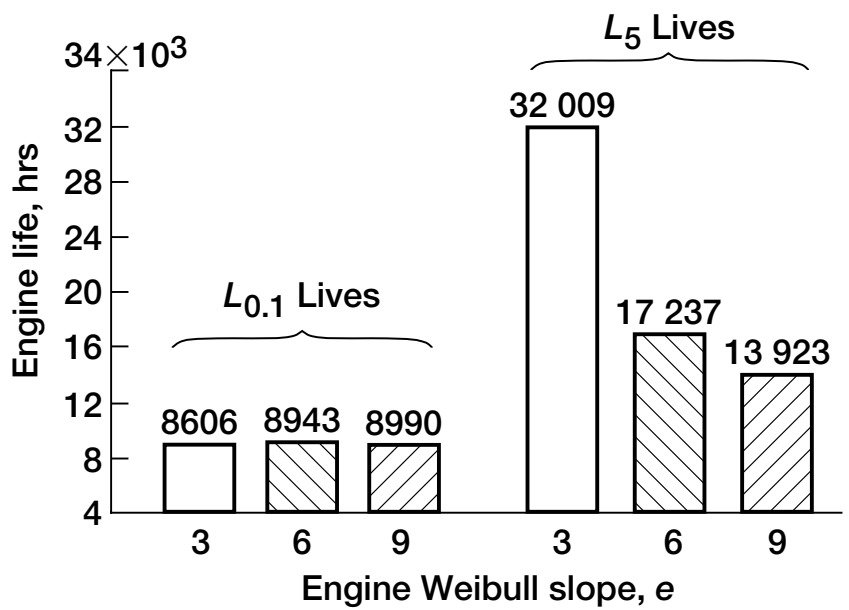

FIG. 7-Effect of engine Weibull slope on engine $L_{0.1}$ and $L_{5}$ lives where all component Weibull slopes equal that of engine. an increase in engine gas temperature (EGT). The predicted $L_{5}$ lives of approximately 17000 and $32000 \mathrm{hr}$, which are dependent on Weibull slope assumed, do correlate with current engine maintenance practices without and with refurbishment, respectively.

\section{Component Lives}

Turbine Disk Life-An error that is frequently made in life prediction, whether for aerospace or non-aerospace applications, is the assumption that the life of a combination of the same components in a system will be the same as that of the single lowest lived component in that system. For a single component, the life of the component is incorrectly taken as the life of the highest stressed element in the body or what is referred to as the "probable point of failure" (ppf).

Halila et al. [2] imply that the design life of the disk is equal to or greater than $36000 \mathrm{hr}$ at a probability of survival of 99.9 percent based on the calculated life at the location of the forward arm air hole for the T1 disk. Using the Halila et al. [2] data which only account for the ppf, we recalculated the disk lives individually and as a system based upon Eq. (3) with $15^{\circ}$ increments (24 segments) ${ }^{4}$ for each disk. For our calculations, we assumed Weibull slopes of 3, 6, and 9. The results are shown in Figure 8. From this figure, one sees that the predicted $L_{0.1}$ system life can vary from 9408 to $24911 \mathrm{hr}$ depending on the Weibull slope (distribution) assumed. The life of a system at a given reliability will be less than the lowest lived component in the system at the same reliability (probability of survival).

\footnotetext{
${ }^{4}$ The life calculations performed were for a single undefined segment of the disk. From Eq. (3), to determine the life of the disk, the number of segments making up the disk need to be known. The repeatability of the geometry and the bolthole pattern around the disk dictated the number of segments assumed for the analysis. For a calculated segment life, the greater the number of segments the lower the disk life and vice versa. This is analogous to a chain of equal links in series where each link carries the same load. For a given load, the greater the number of links, the greater the probability of failure.
} 


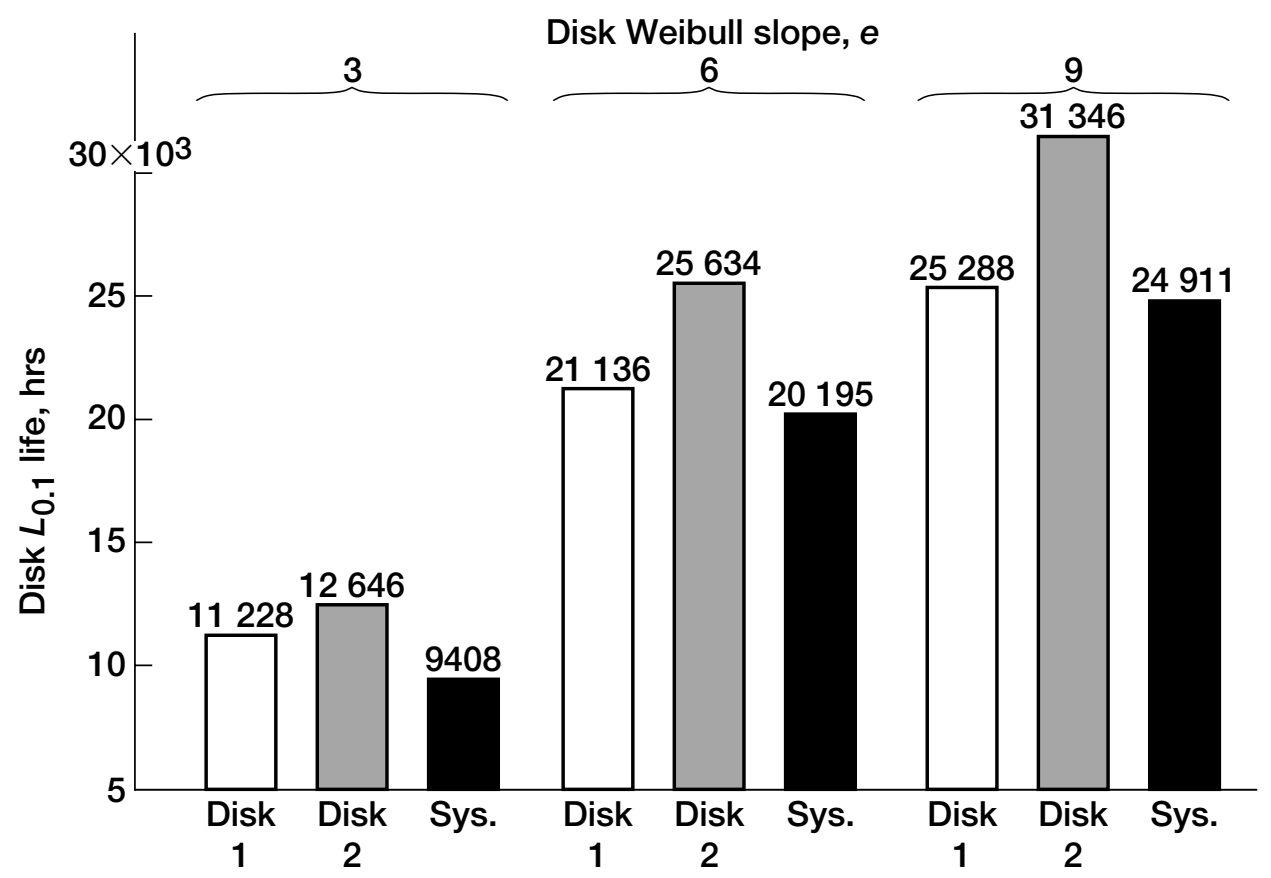

FIG. 8-Effect of Weibull slope on HPT disk $L_{0.1}$ lives.

Blade Life - The HPT blades present a similar problem with regard to determining their lives. Initially, the time to removal of these blades is determined by a creep criterion that is deterministic or, at least, is not assumed to be probabilistic. This criterion is dependent on time exposure at stress and temperature. Material test data are used to predict rupture life based upon calculated stress and temperature. Since throughout an engine cycle these combinations of stress and temperature will vary, the linear damage (Palmgren-Langer-Miner) rule (Eq. (1)) can be applied to determine retirement times for the blade.

Blade coating life is another time-limiting criterion for removal and repair. The blades are usually removed when the engine is removed from service for other reasons and, as necessary, the remaining coating is removed by chemical stripping and/or machining and is replaced. The coating life usually does not dictate blade replacement, only repair.

Besides creep, the limiting time for blade replacement is high cycle fatigue (HCF). As with low cycle fatigue (LCF), HCF is probabilistic. The blades are subject to vibratory stresses combined with mechanical stresses from centrifugal loads, gas aerodynamic loads, and thermal loads. If it is assumed that the effects of load instabilities are quite small relative to the overall blade loads, the linear damage rule (Eq. (1)) can be applied to the operating profile of the blades to estimate their system life.

For the $\mathrm{E}^{3}$-Engine, the HPT blades were designed for a system life of $18000 \mathrm{hr}$ with repairs permissible after the first $9000 \mathrm{hr}$ of engine operation. No reliability was specified by Davis and Stearns [1] or Halila et al. [2] for the $9000 \mathrm{hr}$ service design life. However, we assumed for this discussion and for subsequent calculations that the designated time is at a 99.9 percent reliability for the combination of the total of all the blades contained on disks 1 and 2. On disks 1 and 2, there are 76 and 70 blades, respectively, for a total of 146 blades. Again, assuming Weibull slopes of 3, 6, and 9, we determined the life of an individual blade at a 99.9 percent probability of survival using Eq. (3) where: 
Table 2-Determination of Individual HPT Blade Life as Function of Weibull Slope to Obtain Blade System $L_{0.1}$ Life of $9000 \mathrm{hr}$

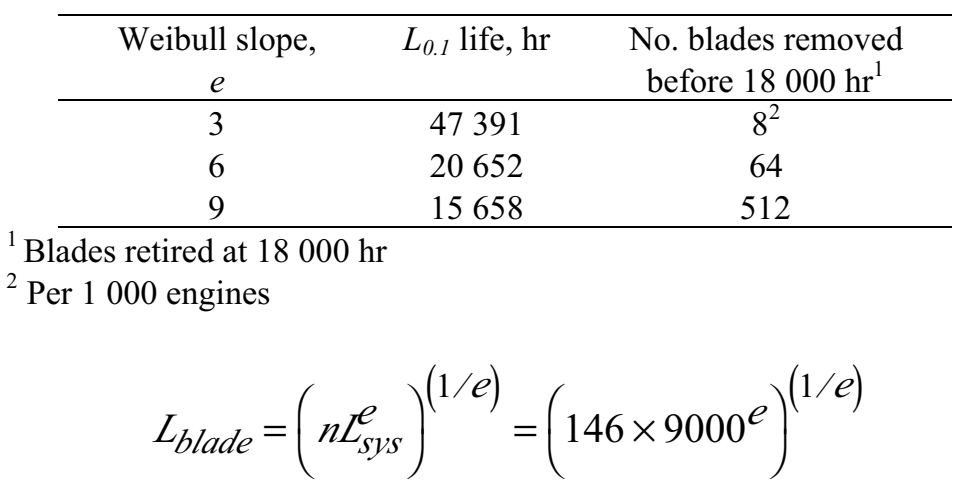

The results are summarized in Table 2.

The individual blade lives necessary to obtain a blade system life of $9000 \mathrm{hr}$ at a 99.9 percent probability of survival ( $L_{0.1}$ life) for Weibull slopes of 3, 6, and 9, were 47391 , 20 652, and $15658 \mathrm{hr}$, respectively. Based on 1000 engines (146 000 blades) with a system blade life of $9000 \mathrm{hr}$ and a retirement time for the blades of $18000 \mathrm{hr}$ constituting the total blade life with repair, it would be expected that 8,64 or 512 blades would be removed for cause prior to this time for Weibull slopes of 3, 6 or 9, respectively. This can best be visualized from the Weibull plots of Figure 5. For the same $L_{0.1}$ life, the number of failures per unit time increased with increases in the Weibull slope.

Other Components - A similar analysis can be performed for the fan blades and hub, quarterstage fan booster disks and blades, high-pressure compressor disks and blades, low-pressure turbine disks and blades, and rolling-element bearings. In fact, this type of analysis has been performed to determine the life of rolling-element bearings individually and as a system for nearly 5 decades [16]. Once all the component lives are determined at a given probability of survival (or at a given replacement rate), the removal rate for cause of the entire engine can be predicted with reasonable engineering certainty.

\section{Summary of Results}

The effect of individual engine component life distributions on engine life prediction was determined. A Weibull-based life and reliability analysis on the NASA Energy Efficient Engine was conducted. The engine's life at a 95 and 99.9 percent probability of survival was determined based upon the engine manufacturer's original life calculations and assumed values of each of the component's cumulative life distributions as represented by a Weibull slope. The lives of the high-pressure turbine (HPT) disks and blades were also evaluated individually and as a system in a like and similar manner. The following results were obtained:

- Variation in each component's statistical distribution and combinations thereof can have a significant effect on engine life prediction. Where service life of each component ranged from 9000 to $36000 \mathrm{hr}$ at a 99.9 percent probability of survival ( $L_{0.1}$ life), the predicted time between removal for varying combinations of component statistical distributions varied from 26 to $8992 \mathrm{hr}$. Hence, knowing the statistical cumulative distribution of each engine component with reasonable engineering certainty is a condition precedent to predicting the life and reliability of an entire engine. 
- For the given design life of each of two HPT disks having ppf equal to or greater than $36000 \mathrm{hr}$ for a system of $15^{\circ}$ increments (24 segments) at a probability of survival of 99.9 percent $\left(L_{0.1}\right.$ life), the predicted disk system $L_{0.1}$ life can vary from 9408 to $24911 \mathrm{hr}$ depending on the Weibull slope assumed. The life of a system at a given reliability will be less than the lowest lived component in the system at the same reliability (probability of survival).

- For the HPT blade system comprising 146 blades and having a $L_{0.1}$ system life of $9000 \mathrm{hr}$, individual blade $L_{0.1}$ life must be equal to 47391,20652 , and $15658 \mathrm{hr}$ for assumed Weibull slopes of 3, 6, and 9, respectively. Based on 1000 engines in service and a retirement time for the blades of $18000 \mathrm{hr}$, constituting the entire life of a blade without repair, it is predicted that 8,64 , or 512 blades would be removed for cause prior to this time for assumed Weibull slopes of 3,6 , or 9 , respectively.

- Where Weibull slopes of all the engine components are equal, the Weibull slope had a minimal effect on engine $L_{0.1}$ life prediction. Predicted engine time for removal varied from 8606 to $8990 \mathrm{hr}$ for Weibull slopes of 3 to 9 , respectively. However, at a probability of survival of 95 percent ( $L_{5}$ life), life decreased with increasing Weibull slope varying from 32009 to $13923 \mathrm{hr}$ for Weibull slopes ranging from 3 to 9 . At the $L_{5}$ life, five percent of the engines in service will have been removed for repair or refurbishment. 



\section{Appendix A-Derivation of Weibull Distribution Function}

As presented in Melis et al. [6] and according to Weibull [3] any cumulative distribution function can be written as

$$
F(X)=1-\exp \{-[f(X)]\}
$$

where $F(X)$ is the probability of an event (failure) occurring. Conversely, from the above the probability of an event not occurring (survival) can be written as

$$
1-F(X)=\exp \{-[f(X)]\}
$$

or

$$
1-F=\exp \{-[f(x)]\}
$$

where $F=F(X)$ and $(1-F)=S$, the probability of survival.

If we have $n$ independent components, each with a probability of the event (failure) not occurring being $(1-F)$, the probability of the event not occurring in the combined total of all components can be expressed from Eq. (A2b) as

$$
\left(1-F_{n}\right)=\exp \{-[\mathrm{n} f(X)]\}
$$

Equation (A3) gives the appropriate mathematical expression for the principle of the weakest link in a chain or, more generally, for the size effect on failures in solids. As an example of the application of Eq. (A3), we assume a chain consisting of several links. Also, we assume that by testing we find the probability of failure $F$ at any load $X$ applied to a "single" link. If we want to find the probability of failure $F_{n}$ of a chain consisting of $n$ links, we must assume that if one link has failed the whole chain fails. In other words, if any single part of a component fails, the whole component has failed. Accordingly, the probability of nonfailure of the chain $\left(1-F_{n}\right)$, is equal to the probability of the simultaneous nonfailure of all the links. Thus,

$$
1-F_{n}=(1-F)^{n}
$$

or

$$
S_{n}=S^{n}
$$

Or, where the probabilities of failure (or survival) of each link are not necessarily equal (i.e., $S_{1} \neq$ $S_{2} \neq S_{3} \neq \ldots$ ), Eq. (A $\left.4 \mathrm{~b}\right)$ can be expressed as

$$
S_{n}=S_{1} \cdot S_{2} \cdot S_{3} \cdot \ldots
$$

and substituting $L$ for $X$ in Eq. (A3) 


$$
S_{n}=1-F_{n}=\exp \{-[n f(L)]\}
$$

Equation (A5) can be expressed as follows:

$$
\ln \ln \left[\frac{1}{\mathrm{~S}}\right]=\ln f(L)+\ln n
$$

It follows that if $\ln \ln (1 / S)$ is plotted as an ordinate and $\ln f(L)$ as an abscissa in a system of rectangular coordinates, a variation of number of links of the test specimen will imply only a parallel displacement but no deformation of the cumulative distribution function. Assuming

$$
f(L)=\left[\frac{L-L_{u}}{L_{\beta}}\right]^{e}
$$

Eq. (A6) becomes

$$
\ln \ln \left[\frac{1}{S}\right]=e \ln \left(L-L_{u}\right)-e \ln L_{\beta}+\ln n
$$

If $L_{u}$, which is the location parameter, is assumed to be zero and $n$ is normalized whereby $\ln n$ is zero, Eq. (A8) can be written as

$$
\ln \ln \left[\frac{1}{S}\right]=e \ln \left[\frac{L}{L_{\beta}}\right]
$$

The form of Eq. (A9) where $L_{u}$ is assumed to be zero is referred to as "two-parameter Weibull." Where $L_{u}$ is not assumed to be zero, the form of the equation is referred to as "threeparameter Weibull." 


\section{Appendix B-Derivation of System Life Equation}

Lundberg and Palmgren [8], using the Weibull equation for rolling-element bearing life analysis, first derived the relationship between individual component lives and system life. The following derivation is based on but is not identical to the Lundberg-Palmgren analysis.

From Appendix A, Eq. (A9)

$$
\ln \ln \left[\frac{1}{\mathrm{~S}_{\mathrm{sys}}}\right]=e \ln \left[\frac{L}{L_{\beta}}\right]
$$

where $L$ is the number of cycles or time to failure.

Referring to the sketch of a Weibull plots in Figure 2, the slope $e$ can be defined as follows:

$$
e=\frac{\ln \ln \left[\frac{1}{S_{\text {sys }}}\right]-\ln \ln \left[\frac{1}{S_{\text {ref }}}\right]}{\ln L-\ln L_{\text {ref }}}
$$

or

$$
\frac{\ln \left[\frac{1}{S_{\text {sys }}}\right]}{\ln \left[\frac{1}{S_{\text {ref }}}\right]}=\left[\frac{L}{L_{\text {ref }}}\right]^{e}
$$

From Eqs. (B1) and (B2b)

$$
\ln \left[\frac{1}{S_{\mathrm{sys}}}\right]=\left[\ln \frac{1}{S_{\mathrm{ref}}}\right]\left[\frac{L}{L_{\mathrm{ref}}}\right]^{e}=\left[\frac{L}{L_{\beta}}\right]^{e}
$$

and

$$
S_{\text {sys }}=\exp \left\{-\left[\frac{L}{L_{\beta}}\right]^{e}\right\}
$$


Referring to Figure 2, for a given time or life $L$, each component or stressed volume in a system will have a different reliability $S$. From Eq. (A4c) for a series reliability system

$$
S_{\text {sys }}=S_{1} \cdot S_{2} \cdot S_{3} \cdot \ldots
$$

Combining Eqs. (B4) and (B5) gives

$$
\exp \left\{-\left[\frac{L}{L_{\beta}}\right]^{e}\right\}=\exp \left\{-\left[\frac{L}{L_{\beta 1}}\right]^{e}\right\} \times \exp \left\{-\left[\frac{L}{L_{\beta 2}}\right]^{e}\right\} \times \exp \left\{-\left[\frac{L}{L_{\beta 3}}\right]^{e}\right\} \times \ldots
$$

or

$$
\exp \left\{-\left[\frac{L}{L_{\beta}}\right]^{e}\right\}=\exp \left\{-\left[\frac{L}{L_{\beta 1}}\right]^{e}-\left[\frac{L}{L_{\beta 2}}\right]^{e}-\left[\frac{L}{L_{\beta 3}}\right]^{e}-\ldots\right\}
$$

It is assumed that the Weibull slope $e$ is the same for all components. From Eq. (B6b)

$$
-\left[\frac{L}{L_{\beta}}\right]^{e}=-\left\{\left[\frac{L}{L_{\beta 1}}\right]^{e}+\left[\frac{L}{L_{\beta 2}}\right]^{e}+\left[\frac{L}{L_{\beta 3}}\right]^{e}+\ldots\right\}
$$

Factoring out $L$ from Eq. (B7a) gives

$$
\left[\frac{1}{L_{\beta}}\right]^{e}=\left[\frac{1}{L_{\beta 1}}\right]^{e}+\left[\frac{1}{L_{\beta 2}}\right]^{e}+\left[\frac{1}{L_{\beta 3}}\right]^{e}+\ldots
$$

From Eq. (B3) the characteristic lives $L_{\beta 1}, L_{\beta 2}, L_{\beta 3}$, etc., can be replaced with the respective lives $L_{1}, L_{2}, L_{3}$, etc., at $S_{\text {ref }}$ (or the lives of each component that have the same probability of survival $S_{\text {ref }}$ ) as follows:

$$
\left[\ln \frac{1}{S_{\mathrm{ref}}}\right]\left[\frac{1}{L_{\mathrm{ref}}}\right]^{e}=\left[\ln \frac{1}{S_{\mathrm{ref}}}\right]\left[\frac{1}{L_{1}}\right]^{e}+\left[\ln \frac{1}{S_{\mathrm{ref}}}\right]\left[\frac{1}{L_{2}}\right]^{e}+\left[\ln \frac{1}{S_{\mathrm{ref}}}\right]\left[\frac{1}{L_{3}}\right]^{e}+\ldots
$$

where, in general, from Eq. (B3)

$$
\left[\frac{1}{L_{\beta}}\right]^{e}=\left[\ln \frac{1}{S_{\mathrm{ref}}}\right]\left[\frac{1}{L_{\mathrm{ref}}}\right]^{e}
$$


and

$$
\left[\frac{1}{L_{\beta 1}}\right]^{e}=\left[\ln \frac{1}{S_{\text {ref }}}\right]\left[\frac{1}{L_{1}}\right]^{e} \text {, etc. }
$$

Factoring out $\left[\ln \left(1 / S_{\text {ref }}\right)\right]$ from Eq. (B8) gives

$$
\frac{1}{L_{\mathrm{ref}}}=\left\{\left[\frac{1}{L_{1}}\right]^{e}+\left[\frac{1}{L_{2}}\right]^{e}+\left[\frac{1}{L_{3}}\right]^{e}+\ldots\right\}^{1 / e}
$$

or rewriting Eq. (B10) results in

$$
\left[\frac{1}{L_{\mathrm{ref}}}\right]^{e}=\sum_{i=1}^{n}\left[\frac{1}{L_{i}}\right]^{e}
$$

Equation (B11) is identical to Eq. (3) of the text. 


\section{References}

[1] Davis, D. Y., and Stearns, E. M., "Energy Efficient Engine Flight Propulsion System Final Design and Analysis," NASA CR-168219, 1985.

[2] Halila, E. E., Lenahan, D. T., and Thomas, T. T., "Energy Efficient Engine High Pressure Turbine Test Hardware: Detailed Design Report," NASA CR-167955, 1982.

[3] Weibull, W., "A Statistical Theory of the Strength of Materials," Ingeniors Vetanskaps Akademien-Handlinger, 1939a, No. 151.

[4] Weibull, W., "The Phenomenon of Rupture in Solids," Ingeniors Vetanskaps AkademienHandlinger, 1939b, No. 153.

[5] Zaretsky, E. V., Smith, T. E., and August, R., "Effect of Design Variables, Temperature Gradients and Speed on Life and Reliability of a Rotating Disk," Trans. ASME, Journal of Vibration, Acoustics, Stress and Reliability in Design, Vol. 111, No. 3, 1989, pp. 311-317.

[6] Melis, M. E., Zaretsky, E. V., and August, R., "Probabilistic Analysis of Aircraft Gas Turbine Disk Life and Reliability," AIAA Trans., Journal of Propulsion and Power, Vol. 15, No. 5, 1999, pp. 658-666.

[7] Zaretsky, E. V., "Fatigue Criterion to System Design, Life and Reliability," Trans. AIAA, Journal of Propulsion and Power, Vol. 3, No. 1, 1987, pp. 76-83.

[8] Lundberg, G., and Palmgren, A., "Dynamic Capacity of Rolling Bearings," Acta Polytechnica, Mechanical Engineering Series, Vol. 1, No. 3, 1947, Stockholm.

[9] Lewicki, D. G., Black, J. D., Savage, M., and Coy, J. J., "Fatigue Life Analysis of a Turboprop Reduction Gearbox," Trans. ASME, Journal of Mechanisms, Transmissions, Automation, and Design, Vol. 108, No. 2, 1986, pp. 255-262.

[10] Zaretsky, E. V., Hendricks, R. C., and Soditus, S., "Weibull-Based Design Methodology for Rotating Aircraft Engine Structures," Ninth International Symposium on Transport Phenomena and Dynamics of Rotating Machinery, Honolulu, Hawaii, Feb. 10-14, 2002, Paper No. DD-ABS-082 (also NASA/TM-2002-211348).

[11] Palmgren, A., "The Service Life of Ball Bearings," Zectsckrift des Vereines Deutscher Ingenieure, Vol. 68, No. 14, 1924, pp. 339-341.

[12] Langer, B. F., "Fatigue Failure From Stress Cycles of Varying Amplitude," Trans. ASME, Journal of Applied Mechanics, Vol. 59, 1937, pp. A160-A162.

[13] Miner, M. A., "Cumulative Damage in Fatigue," Trans. ASME, Journal of Applied Mechanics, Vol. 12, No. 3, 1945, pp. A159-A164.

[14] Weibull, W., "A Statistical Distribution Function of Wide Applicability," Trans. ASME, Journal of Applied Mechanics, Vol. 18, No. 3, 1951, pp. 293-297.

[15] Weibull, W., "Efficient Methods for Estimating Fatigue Life Distribution of Rolling Bearings," Rolling Contact Phenomena, J. B. Bidwell, Ed., Elsevier, New York, 1962, pp. 252-265.

[16] Zaretsky, E. V., Ed., STLE Life Factors for Rolling Bearings, STLE Publication SP-34, Society of Tribologists and Lubrication Engineers, Park Ridge, IL, 1992. 

Public reporting burden for this collection of information is estimated to average 1 hour per response, including the time for reviewing instructions, searching existing data sources, gathering and maintaining the data needed, and completing and reviewing the collection of information. Send comments regarding this burden estimate or any other aspect of this collection of information, including suggestions for reducing this burden, to Washington Headquarters Services, Directorate for Information Operations and Reports, 1215 Jefferson Davis Highway, Suite 1204, Arlington, VA 22202-4302, and to the Office of Management and Budget, Paperwork Reduction Project (0704-0188), Washington, DC 20503.

\begin{tabular}{|l|l|l|}
\hline 1. AGENCY USE ONLY (Leave blank) & $\begin{array}{c}\text { 2. REPORT DATE } \\
\text { August } 2003\end{array}$ & $\begin{array}{r}\text { 3. REPORT TYPE AND DATES COVERED } \\
\text { Technical Memorandum }\end{array}$ \\
\hline
\end{tabular}

4. TITLE AND SUBTITLE

5. FUNDING NUMBERS

Effect of Individual Component Life Distribution on Engine Life Prediction

6. AUTHOR(S)

WBS-22-323-71-00

Erwin V. Zaretsky, Robert C. Hendricks, and Sherry M. Soditus

7. PERFORMING ORGANIZATION NAME(S) AND ADDRESS(ES)

National Aeronautics and Space Administration

John H. Glenn Research Center at Lewis Field

Cleveland, Ohio 44135-3191

8. PERFORMING ORGANIZATION

REPORT NUMBER

E-13591

9. SPONSORING/MONITORING AGENCY NAME(S) AND ADDRESS(ES)

10. SPONSORING/MONITORING

AGENCY REPORT NUMBER

National Aeronautics and Space Administration

Washington, DC 20546-0001

NASA TM-2003-212532

\section{SUPPLEMENTARY NOTES}

Prepared for the Symposium on Probabilistic Aspects of Life Predictions sponsored by the ASTM Committee E08 on Fatigue and Fracture, Miami Beach, Florida, November 6-7, 2002. Erwin V. Zaretsky and Robert C. Hendricks, NASA Glenn Research Center; and Sherry M. Soditus, United Airlines Maintenance, San Francisco, California 94128.

Responsible person, Erwin V. Zaretsky, organization code 5900, 216-433-3241.

12a. DISTRIBUTION/AVAILABILITY STATEMENT

12b. DISTRIBUTION CODE

Unclassified - Unlimited

Subject Categories: 05, 07, 09, 37, 39, and 65

Distribution: Nonstandard

Available electronically at http://gltrs.grc.nasa.gov

This publication is available from the NASA Center for AeroSpace Information, 301-621-0390.

13. ABSTRACT (Maximum 200 words)

The effect of individual engine component life distributions on engine life prediction was determined. A Weibull-based life and reliability analysis of the NASA Energy Efficient Engine was conducted. The engine's life at a 95 and 99.9 percent probability of survival was determined based upon the engine manufacturer's original life calculations and assumed values of each of the component's cumulative life distributions as represented by a Weibull slope. The lives of the high-pressure turbine (HPT) disks and blades were also evaluated individually and as a system in a similar manner. Knowing the statistical cumulative distribution of each engine component with reasonable engineering certainty is a condition precedent to predicting the life and reliability of an entire engine. The life of a system at a given reliability will be less than the lowest-lived component in the system at the same reliability (probability of survival). Where Weibull slopes of all the engine components are equal, the Weibull slope had a minimal effect on engine $L_{0.1}$ life prediction. However, at a probability of survival of 95 percent $\left(L_{5}\right.$ life), life decreased with increasing Weibull slope.

\section{SUBJECT TERMS}

Engine life; Weibull analysis; Turbine; Blade; Disk reliability

17. SECURITY CLASSIFICATION OF REPORT

Unclassified

18. SECURITY CLASSIFICATION
OF THIS PAGE
Unclassified

Unclassified
19. SECURITY CLASSIFICATION OF ABSTRACT

Unclassified
15. NUMBER OF PAGES

25

16. PRICE CODE

20. LIMITATION OF ABSTRACT

Standard Form 298 (Rev. 2-89)

Prescribed by ANSI Std. Z39-18 298-102 

